\title{
Cutting Mechanics of Turning with Actively Driven Rotary Tool
}

\author{
Suryadiwansa HARUN ${ }^{1}$, Naoyuki EDA ${ }^{1}$, Toshiro SHIBASAKA ${ }^{1}$, Toshimichi MORIWAKI ${ }^{2}$, \\ Morihiro HIDETA ${ }^{3}$, Gregory HYATT ${ }^{3}$, Koji OKURA $^{3}$ \\ ${ }^{1}$ Graduate School of Engineering, Kobe University, Japan, 032d968n@stu.kobe-u.ac.jp, shiba@mech.kobe-u.ac.jp \\ ${ }^{2}$ Department of Industrial and Systems Engineering, Setsunan University, Japan \\ ${ }^{3}$ Mori Seiki Co., Ltd., Japan
}

\begin{abstract}
:
In this paper, turning with actively driven rotary tool method was investigated. With this method enables programmable control the tool rotational speed so that elevated tool speed is possible. The main purpose of the present work is to experimentally examine influences of machining conditions especially the tool rotational speed and direction upon the cutting force components, the chip formation and the cutting temperature. Experimental results show that cutting temperature decreases with an increase in the tool rotational speed in a certain speed range. The change in tangential force against the tool rotational speed is not so large than radial and axial force. Increase in the tool rotation in $\mathrm{CCW}$ direction exited chatter due to the large radial force.
\end{abstract}

Keywords: Turning with actively driven rotary tool; Cutting temperatures; Cutting forces; Chip formation

\section{Introduction}

In advanced manufacturing technology, high machining productivity can be achieved on increasing the cutting speed. However, cutting temperature is one of the limiting factors in this effort. Many researches have been carried out to seek effective methods to overcome cutting temperature rise when high-speed cutting is applied. In general, high cutting temperature can be reduced by using cutting fluids but they create environmental and health concerns. The other method is using high wear resistance cutting tool materials such as coated and CBN tools. One of the novel methods to decrease the cutting temperature as well as to increase the machining productivity is to use a rotary cutting tool in turning. As the cutting tool rotates and it is cooled during the non-cutting time in one rotation of the tool, it is expected that the temperature of the tool will decrease compared with conventional cutting. It is also expected that the rotary cutting tool can be used for high speed cutting of difficult-to-cut materials such as nickel based and titanium based alloys.

Several types of the rotary cutting tools have been developed in the past, which are basically classified into two types namely actively driven [1-5] and self-propelled [6-8] tools. In the driven tool, the rotational motion of the insert tool is provided by an external source such as a motor spindle mechanism, while the self-propelled tool is driven primarily by the cutting forces acting on the insert tool. An oblique angle is essential to induce the rotary motion in self-propelled tools. However, the selfpropelled type of the rotary tool needs to have a large inclination angle to the cut surface to be rotated, and its rotational speed depends on machining condition. In comparison with the turning with self-propelled tool, turning with actively driven rotary tool gives more advantages. Because of the tool rotational speed and cutting speed are controlled by external power so that they can be changed easily and elevated. Therefore, high machining productivity can be achieved.

Despite those studies have showed the driven rotary tool has a potential, it has not been applied in real production process for several reasons: (1) By the past researchers [1-3], the driven rotary tool was only developed on the conventional machine tool, which is lack in stiffness, flexibility and productivity. (2) Machine tools were not available which could enable programmable control of inclination angle, offset height, and tool rotational speed. (3) The state of art of cutting with driven rotary tools is still at pre-matured stage, and it requires systematic researches to apply the technology to actual production.

In order to make it more applicable to the real production, the driven rotary tool method has been further developed $[4,5]$. In this method, the machine tool provides the programmable control of inclination angle, offset height, cutting speed, and tool rotational speed and direction.

The main purpose of the present work is to experimentally investigate influences of machining condition especially the tool rotational speed and direction on the magnitude of the cutting force components, the chip formation and the cutting temperature.

\section{Experimental procedure}

\subsection{Experimental equipment and condition}

In turning with actively driven rotary tool used in this work could enables two positions of the tool cutting edge relative to the work. The inclination angle $\mathrm{i}$ of the tool holder and offset height $\mathrm{h}$ are defined as shown in Fig 1. When the tool rotates from points of large chip thickness to point of small chip thickness, the rotational direction of tool is defined to be counterclockwise. The work velocity $\mathrm{V}_{\mathrm{w}}$, the tool rotational speed $\mathrm{V}_{\mathrm{T}}$ and the feed rate $\mathrm{f}$ are shown in Fig. 1.

Figure 2 shows a photograph of the experimental equipment. In order to measure the cutting force, an additional spindle is mounted on the table of a vertical machining center (Hitachi Seiki VM-3) to which the workpiece is attached as shown in Fig. 2. The NT series 
of integrated Mill Turn machine center, Mori Seiki NT4200 DCG, as driven rotary turning machine that applicable for industry was also utilized in order to measure the cutting temperature.

A $16 \mathrm{~mm}$ diameter insert made of PVD Coated Cermet having a relief angle of $11^{\circ}$ was used. The work materials employed for the cutting experiment was plain carbon steel JIS:S45C. Cutting forces were measured using the piezo-electric force transducers of the force ring dynamometer. Cutting temperatures were measured utilizing embedded constantan wire-work thermocouple system. The major cutting conditions are summarized in Table 1.
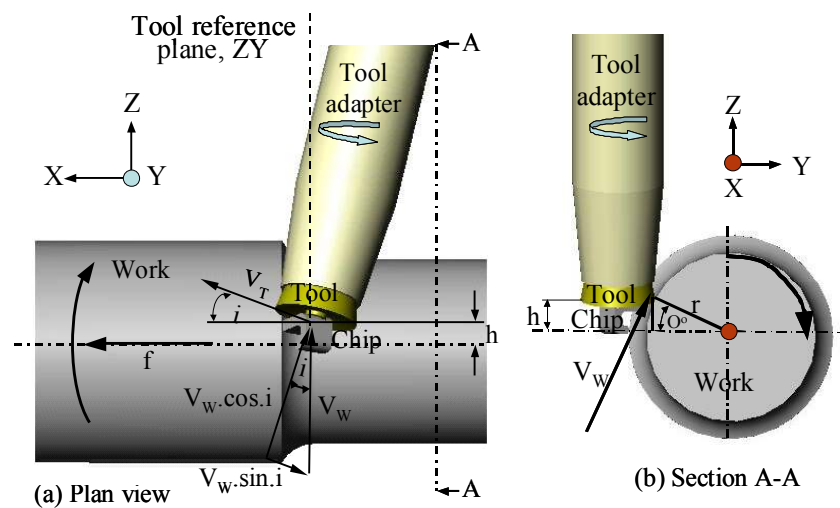

(b) Section A-A

\subsection{Cutting temperature measurement}

A constantan wire was embedded in the workpiece as shown in Fig. 3. The principle of this method is that when the workpiece is cut, the wire is also machined, and a thermoelectric junction (emf) is formed between the constantan wire and the workpiece at contact area. The work and constantan wire must be electrically isolated from tool with using a ceramic coating. To record cutting temperature signals at contact area between the workpiece and tool, the constantan wire and the workpiece wire were connected to a slip ring through a hole at center of the work spindle and then they were connected to an oscilloscope. High sampling frequency of $500 \mathrm{kHz}$ was used. To embed the constantan wire into a workpiece, the workpiece must be cut sliced into two parts, and then a V slot was machined along the central axis of one of parts as shown in Fig. 3.

In wire-work thermocouple calibration, the type $\mathrm{K}$ standard thermocouple (chromel-alumel couple) was clamped between the workpiece point and a piece of the constantan wire, then the junction was heated inside the furnace. The correlation between the temperature and the emf generated at the contact area between the constantan wire and the tool is found to be as shown in equation (1).

$$
\mathrm{V}=0.0562 \mathrm{~T}
$$

where $\mathrm{V}$ is the output voltage in $\mathrm{mV}$, and $\mathrm{T}$ is temperature in ${ }^{\circ} \mathrm{C}$.

An example of the raw data of output signals detected by embedded constantan wire-work thermocouple technique is shown in Fig. 4. This output signal was obtained periodically that the interval between each signal is equal to frequency in which the cutting edge touches the constantan wire inside the workpiece each one revolution of work. As shown in figure 4, another important parameter is the cooling time, which is defined as amount of time that needed when the high temperature at the contact point area inside the workpiece gradually reduced to the ambient temperature $(1.3 \mathrm{mV})$.

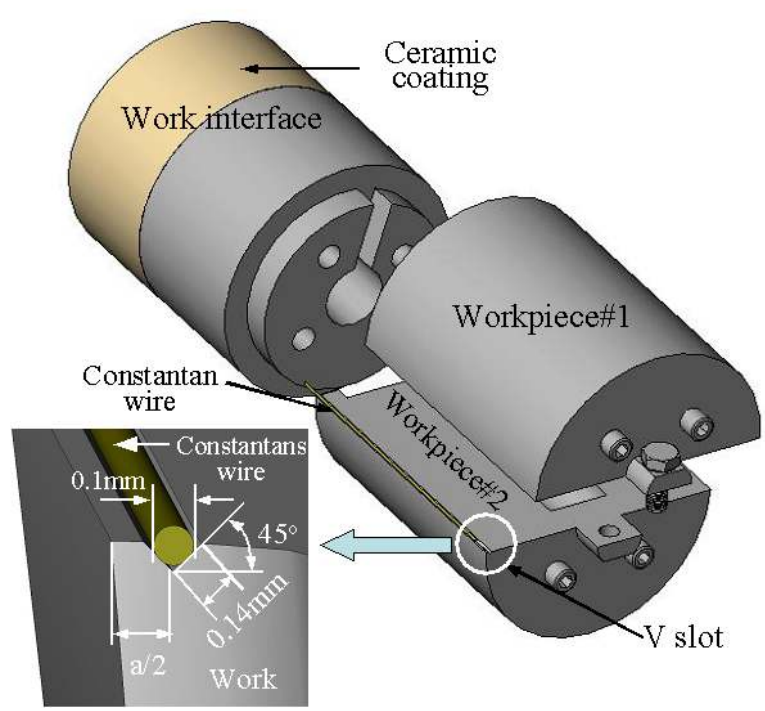

Figure 3: Cutting temperature experimental set-up. 


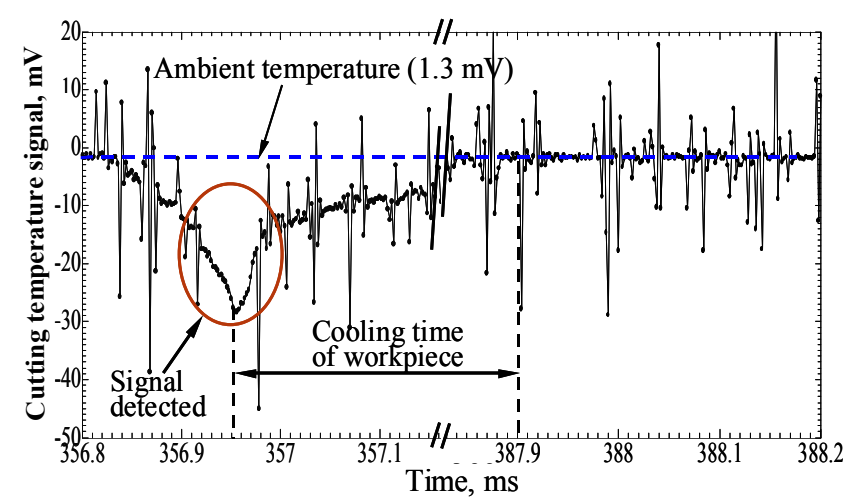

Figure 4: Sample of signal detected during driven rotary tool turning (Cutting conditions: $\mathrm{V}_{\mathrm{W}}=150 \mathrm{~m} / \mathrm{min}$, $\mathrm{V}_{\mathrm{T}}=25 \mathrm{~m} / \mathrm{min}, \mathrm{f}=0.2 \mathrm{~mm} / \mathrm{rev}, \mathrm{DOC}=1 \mathrm{~mm}$ )

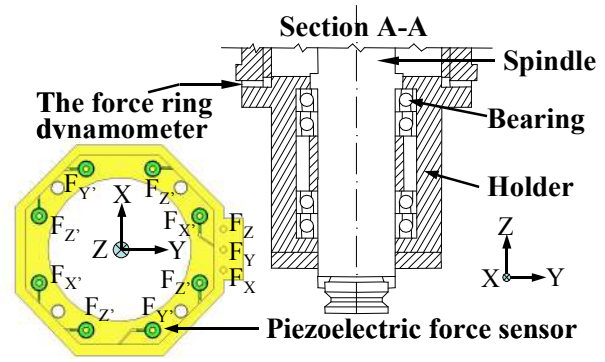

Figure 5: Built-in type cutting sensor system

\subsection{Cutting force measurement}

The three cutting force components of the tangential force, $F_{Z}$, the axial force $F_{X}$ and the radial force $F_{Y}$ were measured with the force ring dynamometer as shown in Fig. 5. The force ring is composed of eight piezoelectric force sensors embedded in ring like frame, which it is installed at the fixing point of the main spindle head as shown in Fig. 5. Calibration of the dynamometer was carried out prior to the cutting tests to calibrate the sensitivities of the dynamometer with use of the table-type dynamometer and to compensate the cross talks of the output signals.

\section{Result and discussion}

Fig. 6 shows the photograph of chips obtained during machining with various tool rotational speeds. Interestingly, the chips formed at the non rotating tool are colored in the dark-bluish that caused by oxidation, also the dark-bluish of chip colour was obtained for case of a tool rotational speed of $25 \mathrm{~m} / \mathrm{min}$, but its color did not dominant in bluish. This means that those chips were formed at higher temperature as compared with those formed at the tool rotational speed of 50 and $75 \mathrm{~m} / \mathrm{min}$, which are colored in brownish-purple.

In addition, with the increase of the tool rotational speed, the helix angle of the chips as shown in Fig. 6 was increased, then it seems that the chip flow becomes smooth, also its flow direction was changed. This indicates the cutting mechanics change from orthogonal to oblique cutting. This leads to an increase in the effective rake angle.

Fig. 7 shows the cutting temperature signal and cooling time of workpiece plotted against the tool rotational speed when machining plain carbon steel $(\mathrm{S} 45 \mathrm{C})$ under a fixed cutting speed of $150 \mathrm{~m} / \mathrm{min}$. It can be seen from this figure that tool rotational speed has a significant effect on cutting temperatures. The cutting temperature decreases with increasing tool rotational speed in the tool rotational speed range from 0 to $75 \mathrm{~m} / \mathrm{min}$. It is understood that the increase of the effective rake angle causes the decrease of cutting temperature.

In addition, when the tool rotational speed increases, the cooling time became short with increase of the tool rotational speed, because of the fall of the cutting temperature. To understand the characteristic of cooling abilities of driven rotary tool, definition of the cooling time is determined as described in section 2.2. However, it was assumed that the effect of cooling at the ambient temperature is the same to both the tool and the workpiece during dry machining. In case of the tool rotational speed of $75 \mathrm{~m} / \mathrm{min}(1500 \mathrm{rpm})$, the tool cutting edge needs time of $40 \mathrm{~ms}$ for entering to cutting zone. As compared with the cooling time of $23 \mathrm{~ms}$ at this condition as shown in Fig. 7 , it is clear that the cutting edge was sufficiently cooled down before entering the cutting zone. However, if the tool rotational speed is higher than $75 \mathrm{~m} / \mathrm{min}$, the cutting temperature of cutting edge may be continue to rise due to the heat accumulation. This means that the cooling of the tool edge includes the upper limit.

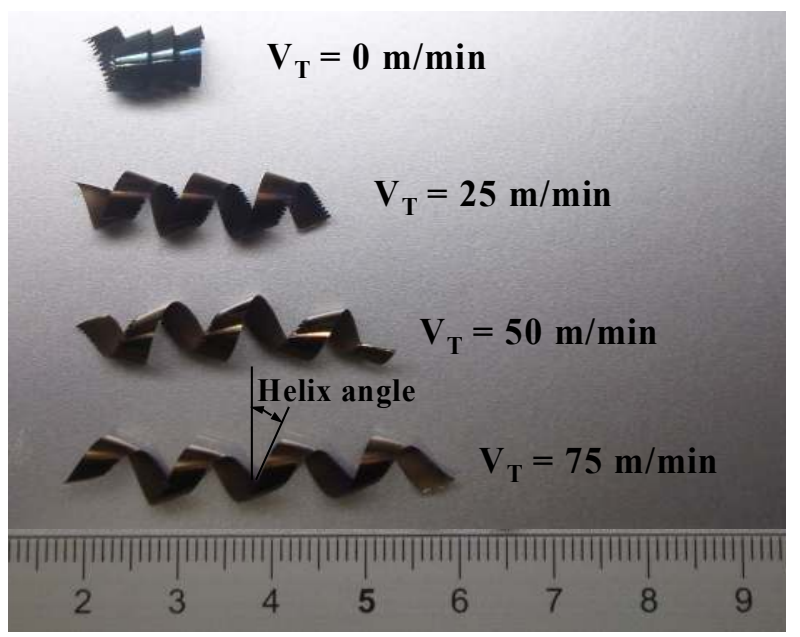

Figure 6: Photographs of chips obtained during machining with various tool rotational speed.

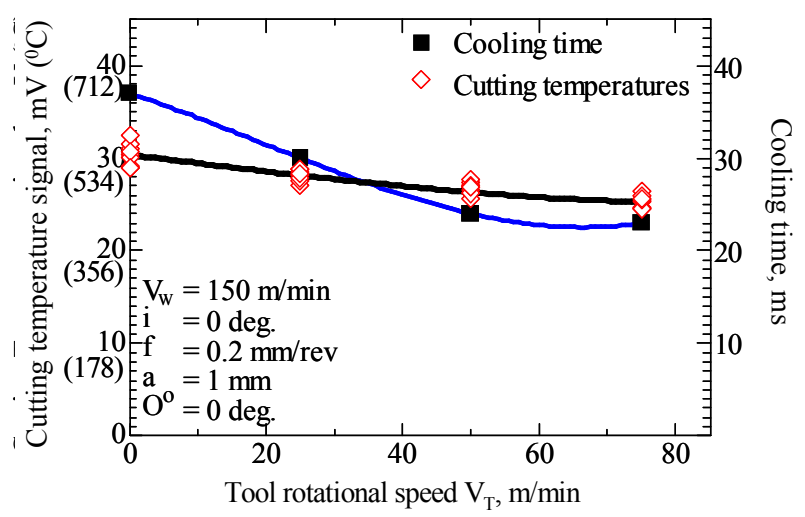

Figure 7: Effect of tool rotational speed on cutting temperatures 


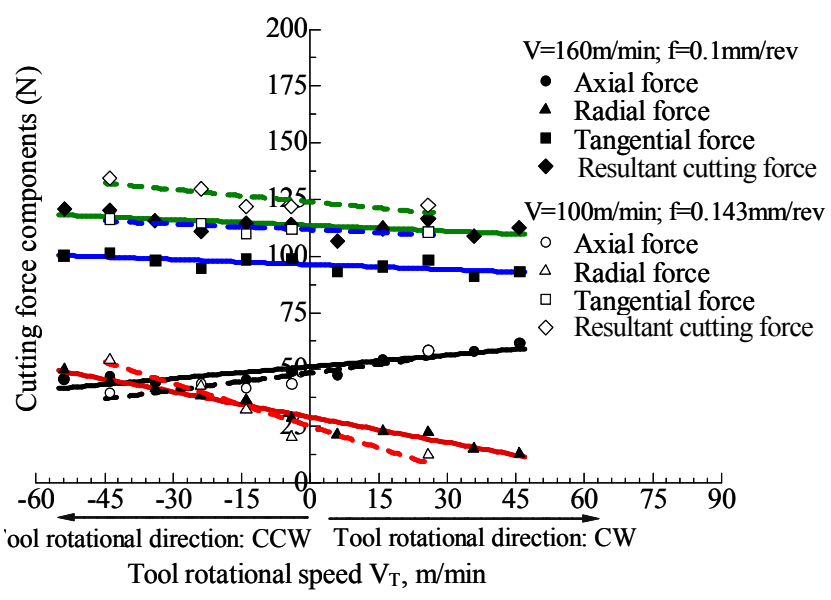

Figure 8: Average force components plotted against tool rotational speed.

Fig. 8 shows the cutting forces plotted against the tool rotational speed when the tool was rotated in both the clockwise $(\mathrm{CW})$ and the counterclockwise (CCW) directions. The tangential and radial forces decrease with an increase in the tool rotational speed. However, the change of tangential force against the tool rotational speed is not so large as the change in radial force. The axial force increases with an increase in clockwise tool rotational speed. When the tool is rotated in $\mathrm{CW}$ direction, the tangential velocity has the same direction with feed direction. That results in large axial direction velocity, which is the sum of the tangential velocity and feed speed. This factor increases the axial force component with an increase in the tool rotational speed. As consequently of magnitude all cutting force component, the resultant cutting force decreases with an increase of tool rotational speed. The change of resultant cutting force against the tool rotational speed is also not so large.

However, the chip surface that produced during machining for both tool rotational direction of $\mathrm{CCW}$ and $\mathrm{CW}$ is rather different as shown in Fig. 9. The chatter mark was observed on the chip surface during machining with tool rotational direction of $\mathrm{CCW}$, while the smooth chips surface was observed when the tool rotated in the opposite direction. It was seemed that the unstable cutting or chatter occurred during machining with tool rotational directions of $\mathrm{CCW}$ due to the large radial force.

\section{Conclusions}

Turning with actively driven rotary tool method with programmable control the tool rotational speed was carried out. The influence of machining conditions especially the tool rotational speed and direction upon the cutting force and temperature was experimentally examined. Major experimental observations are as follows: 1. The cutting temperature decreases with the increase of tool rotation speed in a certain speed range.

2. The change in tangential and resultant cutting force against the tool rotational speed is not so large as compared with that of radial and axial force.
3. The radial forces decreases with an increase in tool rotational speed, while the axial force increases with an increase in tool rotational speed.

4. Chatter marks were observed when the tool rotational speed with tool rotational direction of $\mathrm{CCW}$ increased.

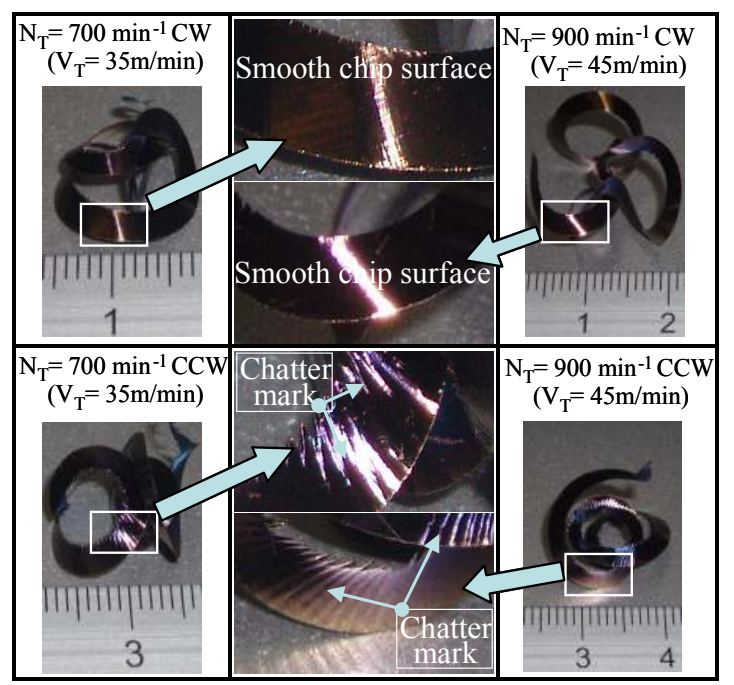

Figure 9: Photographs of chips obtained when different tool rotational direction. $\left(\mathrm{V}_{\mathrm{W}}=160 \mathrm{~m} / \mathrm{min}, \mathrm{f}=0,1 \mathrm{~mm} / \mathrm{rev}\right.$, $\mathrm{a}=0.5 \mathrm{~mm}, \mathrm{i}=0 \mathrm{deg}, \mathrm{O}^{\circ}$, Work $=\mathrm{S} 45 \mathrm{C}$ )

\section{References}

[1] Shaw, M.C., Smith, P.A., Cook, N.H., 1952, The Rotary Cutting Tool, Transaction of the ASME 74 1065-1076.

[2] Lei, S.T, Liu, W.J., 2002, High-speed Machining of Titanium Alloys Using the Driven Rotary Tool, Int. J. Mach. Tools Manuf., 42, pp. 653-661

[3] Yasui, H., Hoda, S., 2005, Cutting Characteristics in Edge Moving Type of Long Life Precision Cutting Method, Proceedings of the $5^{\text {th }}$ euspen International Conference, Montpellier, France, pp. 595-598

[4] Muraki et al., 2004, High Speed Turning of High Temperature Alloys by Using INTEGREX, The $5^{\text {th }}$ Manufacturing \& Machine Tool Conference, pp. 145-146 (in Japanese)

[5] Kato et al., 2006, Rotary Cutting of Difficult-to-Cut Materials by Multi Tasking Lathe, The $6^{\text {th }}$ Manufacturing \& Machine Tool Conference, pp. 141-142 (in Japanese)

[6] Chen, P., 1992, Cutting temperatures and Forces in Machining of High Performance Materials with Selfpropelled Rotary Tool, JSME International Journal, Series III 35 (1), pp. 180-185

[7] Kishawy, H.A., Wilcox, J., 2002, Tool Wear and Chip Formation During Hard Turning with Selfpropelled Rotary Tools. Int. J. Mach. Tools Manuf., 43, pp. 433-439

[8] Dessoly, V., Melkote, S.N., Lescalier, C., 2004, Modeling and Verification of Cutting Tool Temperatures in Rotary Tool Turning of Hardened steel. Int. J. Mach. Tools Manuf., 44, pp. 1463-1470 